\title{
Lance Design for Scrap Melting Aggregates
}

\author{
Ladislav Kovar, Pavel Novak*, Tomas Hapla
}

\begin{abstract}
Metallurgical aggregates, which are used for metal waste melting, are equipped with lances for blowing gaseous media. These gaseous media allow especially scrap melting and intense homogenization of the resulting melt. In connection with this, the blowing systems are developed both for blowing of gaseous media itself on the bath surface or into the melt and for blowing of the gas mixture with powdered substances. When designing the blowing systems and the individual lance tips and nozzles, it is necessary to respect certain criteria, the derivation of which is based on long-term experience and acquired knowledge in this field. The submitted paper summarizes the design recommendations, including the determination of the selected design characteristics of the nozzles for blowing gaseous media on the bath surface in the metallurgical aggregate. These design characteristics help designers and engineers to design systems that meet the high demands on quality, efficiency and operational reliability.
\end{abstract}

Keywords: blowing lance; gas blowing; iron scrap melting; metal scrap processing; nozzle; steel production

\section{INTRODUCTION}

If gaseous medium is blowed into metallurgical aggregate for waste metal processing, then we want to achieve certain technological effect at melt processing or gaseous products. Within this context the character of mutually interaction between blown gas and melt or generally told by environment inside of reactor, which is substantially affected by lance design, is very much important. Wide spectrum of various lance designs are used in thermal reactors at different industrial branches which are intended to different purposes [1-5]. In the following text we will focuse most of all to refine lances used in metallurgical aggregates for scrap iron processing.

\section{FACTORS AFFECTING REFINE LANCES DESING}

Metallurgical aggregates for iron waste processing (melting) are equipped with various types of lances for gaseous media blowing. Design of the lances is given by the purpose for which the lances are designed. The main technological process is provided by the so-called refining lances by which refining oxygen is blown to the surface or below the melt level. It depends on the construction of the aggregate $[6,3]$.

Lance design has a significant influence on the parameters of the output stream of refining oxygen, which significantly influences not only the metallurgical parameters but also the economic indicators of the aggregate $[7,8]$.

It is therefore necessary that the lance design respects also requirements for lance service life and reliability of the production unit in addition to the above-mentioned indicators. Multinozzle lances (lance tips) with convergentdivergent and cylindrical nozzles (see Fig. 1) are designed for refining oxygen blowing, the number of which depends on the intensity of the $\mathrm{O}_{2}$ blowing and in case of oxygen converter there are from three to six nozzles. The mutual position of the nozzles depends on the design of the lance tip. When designing and assessing nozzle function, we proceed with the following parameters:
- maximum $\mathrm{O}_{2}$ mass flow rate through lance and the corresponding $\mathrm{O}_{2}$ resting pressure in the lance,

- optimum number of nozzles and cross-sections ratio,

- static pressure value in front of the nozzle,

- corresponding value of the flow pulse and the action coefficient of the outlet stream on the melt bath,

- dimensions of the reactor working profile (spraying, angle between nozzles),

- the area on the bath surface which is affected by the outlet stream and the penetration of the $\mathrm{O}_{2}$ outlet stream into the melt.

Lances for blowing of gaseous media on the melt surface in the working space of high-temperature reactors for metal making are exposed to severe working conditions [9]. In the case of oxygen blowing into the steel bath, there is intensive heat generation, metal and slag spraying on the lance tip [10], and at the same time waste gases are released. It is reported that the surface temperature of the bath (reaction zone) reaches values from 2000 to $2500{ }^{\circ} \mathrm{C}$ [11] and the temperature difference between the remaining volume of the bath is in the range of 400 to $700{ }^{\circ} \mathrm{C}$ [12]. Operating experiences shows that the following factors have a decisive impact on the service life and perfect function of the lance:

- radiation effect of the bath and reactor lining,

- thermal effect of exhausted gaseous products,

- effect of melt spraying on the lance tip,

- aerodynamic characteristics of the lance,

- position of the nozzle in the workspace - distance of the nozzle from the bath surface,

- quality of the materials used for lance manufacturing,

- manufacturing method,

- blowing intensity,

- number, shape and dimensions of individual nozzles in the lance,

- design of the cooling system (central, peripheral).

All these factors are related to the heat load of the lance and especially its tip. The outer surface of the lance is therefore exposed to a high heat load. To prevent breakage of the lance material, we must keep the material temperature 
within the appropriate limits and hence there is the need to cool the lance. Lance inner surface is intensively cooled.

Water is used as the cooling medium. However, the lance material is exposed to high thermal stresses, which may cause cracks especially at the weld points between the copper lance tip and other steel parts. The design of the lances should meet the following requirements:

- simplicity with regard to production and assembly,

- use of suitable materials,

- minimum heat consumption from the reactor working space,

- optimal media supply with respect to pressure losses,

- optimal shape of the cooling system, avoiding incrustation and excluding film boiling,

- low noise intensity,

- as small splash and melt ejection as possible together with maximum oxygen utilization,

- as long service life as possible, service life should not be lower than the duration of the high temperature reactor campaign.

\section{FORGED AND CAST REFINING LANCES TIPS}

It is said that in the case of the basic oxygen furnaces, the lance service life is about several hundred heats. It may be from 100 to 500 heats and it depends on many individual parameters of steel melting shop [11].

The material used to manufacture lance tips is electrolytic copper [13]. It is a material which has a high thermal conductivity and therefore the thermal stresses do not appear at such intensity as it would be in the case of other materials. Conversely, it was shown that the deoxidation elements such as e.g. phosphorus, which are contained in a limited amount in the copper acts against diffusion of oxygen into the surface of the lance tip and thus prevent cracking. Although these small amounts of chemical elements reduce, to a certain extent, the thermal conductivity, they can, on the other hand, prolong the service life of the lance.

The tips of the upper refining lances of the steelmaking aggregates (LD converters, heard furnaces. EAF) are, at the present time, manufactured in the form of forgings and (or) castings [12]. Forgings have to be machined to the final form, and the individual parts are then soldered and welded together.

Examples of the lance tips designed for so called upper blowing to the oxygen converter and which consist of several forgings are shown in the Fig. 1 and Fig. 2.

While the lance tip in Fig. 1 consists of six forged parts and has six connecting points (nine places for total lance head assembly), in Fig. 2 there is a lance tip consisting of three forged parts (Fig. 3) and it has only three connecting points (six places for total lance tip assembly).

Another advantage of the lance tip in Fig. 2 is the fact that the connecting plane between the inlet and the outlet part is moved further from the front face of the lance tip, thereby making it better protected from the thermal load from the front face of the lance tip.

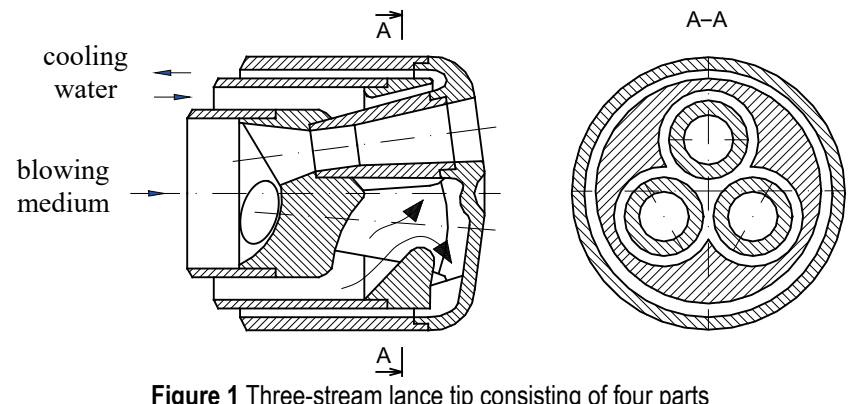

Figure 1 Three-stream lance tip consisting of four parts
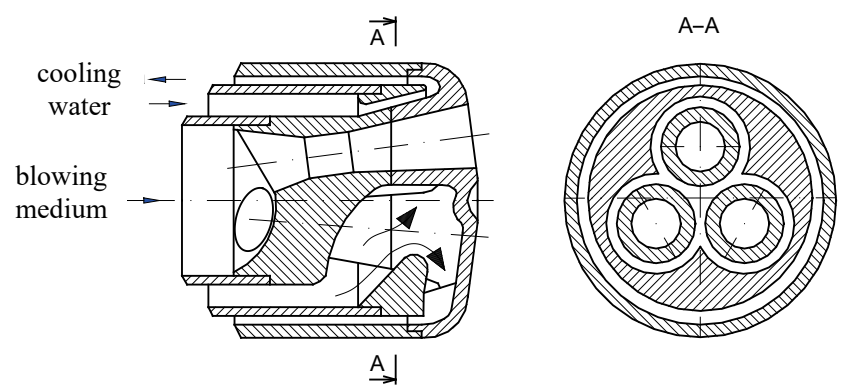

Figure 2 Three-stream lance tip consisting of three parts
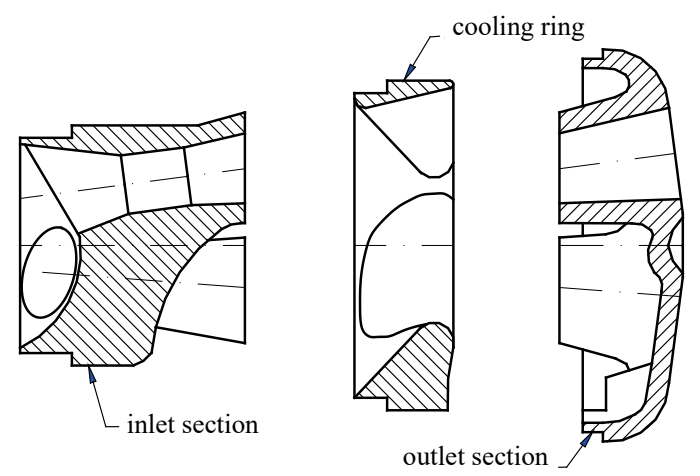

Figure 3 Main parts of three-stream lance tip from Fig. 2

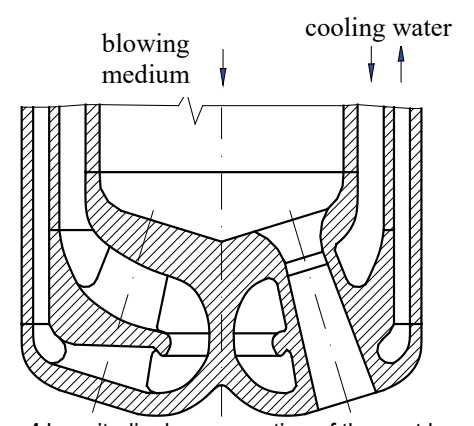

Figure 4 Longitudinal cross-section of the cast lance tip

Cast components, on the other hand, save material, reduce production costs and simplify production and assembly. An example of a cast lance tip is shown in Fig. 4 and Fig. 5.

\section{COOLING OF REFINING LANCES}

The cooling system design is of great importance for increasing the lance service life. Lances are cooled by technical water at a pressure of 0.5 to $1.0 \mathrm{MPa}$. Cooling water 
velocity inside the lance tip is in the range of 1.8 to $6 \mathrm{~m} / \mathrm{s}$. Stagnation areas of the cooling water flow should not be in this system, as the bubble boil then change to the film boil and thus the coefficient of heat transfer from the nozzle wall to the cooling water decreases sharply and the lance tip may be burnt through.

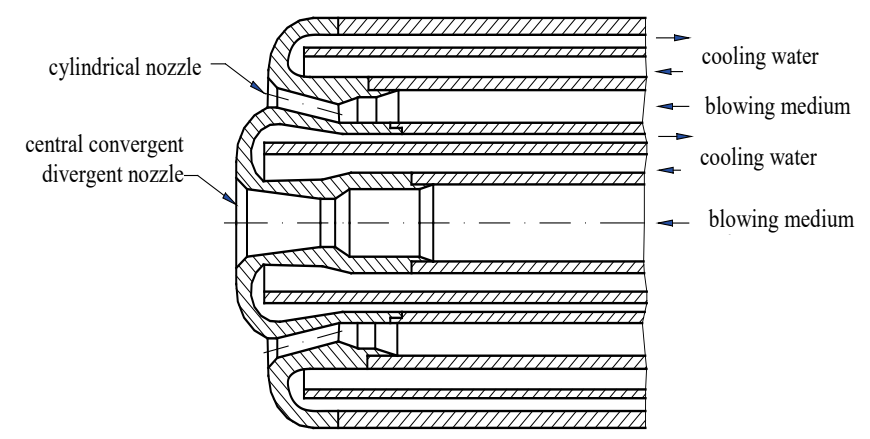

Figure 5 Multinozzle lance tip with central convergent-divergent nozzle

Under operating conditions there are thermodynamic changes in both the working space of the high temperature aggregate and the parameters of the cooling water. These are in particular the heat transfer coefficient from the working space to the lance tip material, the cooling water flow velocity and the purity of the inner walls changes.

Good cooling of the lance and inner nozzles also depends on the thickness of the walls. The thickness of the lance tip wall depends on its dimensions, design, construction, production technology and type of use, and ranges from 6 to $12 \mathrm{~mm}[12]$.

Because of lance high heat load the thermal stresses arise during operational period, which may ultimately lead to the deformation of the particular outer tube [14]. Bellows or stuffing compensators are used to compensate these adverse effects of thermal expansion.

If we go back to the layout (design) of the lance tips in the Fig. 1 and Fig. 2, then cooling water is directed through the cooling rings, which can be divided or in whole.

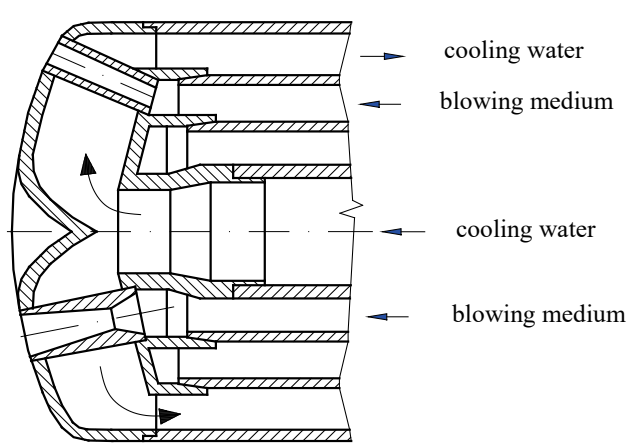

Figure 6 Multinozzle lance tip with central front part cooling

Structural design of cooling channels must ensure continuous velocity changes of cooling water flow in the whole area of cooling ring. Cooling water velocity gradually increases and reaches a maximum when entering into the output annulus formed by the lance outer pipe and the pipe which divides water inlet and outlet.
Central convergent-divergent nozzle with a single or two-layer nozzle arrangement (see Fig. 5) or profiled nozzles with a central cooling system (see Fig. 6) are lance tips designed to increase the cooling effect.

\section{RECOMMENDATIONS FOR MASS FLOW AND TOTAL PRESSURE IN FRONT OF NOZZLES SELECTION}

Assuming that the stagnation pressure of the blown oxygen in front of the nozzle $p_{0}$ will be in the range of 0.6 to $1.3 \mathrm{MPa}$ and the mean value of the oxygen blowing intensity will be $3 \mathrm{~m}_{\mathrm{N}}{ }^{3} / \mathrm{t} \cdot \mathrm{min}$, then for determination of oxygen mass flow rate for oxygen converter derived regression dependency which is expressed as a function of the maximum value of the oxygen mass flow rate $Q_{\mathrm{m}-\max }(\mathrm{kg} / \mathrm{s})$ to the weight of the melt $G_{\text {tav }}(\mathrm{t})$ is used in following shape:

$Q_{\mathrm{m}-\max }=0.0731 \cdot G_{\mathrm{tav}}^{0.996}$

Above equation was derived from the parameters of operated oxygen converters.

In the case of hearth furnaces, the following parameters of blown oxygen were considered:

- $\quad$ pressure of blown oxygen in front of the nozzle $p_{0}=0.6$ up to $1 \mathrm{MPa}$,

- the intensity of blowing will be around $1.2 \mathrm{~m}_{\mathrm{N}}{ }^{3} / \mathrm{t} \cdot \mathrm{min}$

For hearth furnace relation listed below is recommended:

$Q_{\mathrm{m}-\max }=0.0086 \cdot G_{\mathrm{tav}}^{1.208}$

Value of the oxygen stagnation pressure before the nozzle $p_{\mathrm{o}}(\mathrm{MPa})$ is another characteristic which is one of the determining parameters of the flow momentum values and also of blown oxygen concentration.

For converter operation following relation was established:

$$
p_{\mathrm{o}}=0.6755 \cdot G_{\mathrm{tav}}^{0.104}
$$

$p_{0}$ - oxygen stagnation pressure before the nozzle (MPa).

For hearth furnace an analogous relation is valid:

$$
p_{\mathrm{o}}=0.5041 \cdot G_{\mathrm{tav}}^{0.107}
$$

\section{RECOMMENDATIONS FOR NOZZLE GEOMETRY SELECTION}

Convergent-divergent nozzles with the neck of a cylindrical shape are the most commonly used. Diameter of the cylindrical shape neck together with nozzle outlet diameter are other important characteristics.

Important thing is that in design flow mode of oxygen through the nozzle and considered one-dimensional isentropic flow of ideal gas without considering flowing losses so called flow critical state occurs in the throat. 
Throat diameter is then nozzle critical diameter $d_{\mathrm{kr}}$. Value of critical diameter $d_{\mathrm{kr}}(\mathrm{m})$ is calculated from known values of stagnation pressure $p_{0}(\mathrm{MPa})$ and stagnation temperature $T_{0}(\mathrm{~K})$ at corresponding oxygen mass flow $\left(Q_{\mathrm{m}}\right.$ max) and at selected number of nozzles in lance tip $n$ (1) according following relation.

$Q_{\mathrm{m}-\max }=n \cdot S_{\mathrm{kr}} \cdot \frac{p_{\mathrm{o}}}{\sqrt{T_{0}}} \cdot\left(\sqrt{\frac{2 \kappa}{\kappa+1} \cdot R}\right) \cdot\left(\frac{2}{\kappa+1}\right)^{\frac{1}{\kappa-1}}$

After substituting for $\kappa$ (for oxygen $\kappa=1.4$ ) and $R$ (for oxygen $R=259.78$ ) and editing we can write the following expression for $n$ nozzles

$Q_{\mathrm{m}-\max }=0.042483 \cdot n \cdot S_{\mathrm{kr}} \cdot \frac{p_{\mathrm{o}}}{\sqrt{T_{0}}}$

This expression can also be expressed depending on the critical diameter $\left(d_{\mathrm{kr}}\right)$ of the nozzle (see Fig. 9).

$Q_{\mathrm{m}-\max }=0.033366 \cdot n \cdot d_{\mathrm{kr}} \cdot \frac{p_{\mathrm{o}}}{\sqrt{T_{0}}}$

Among the number of nozzles in the lance tip $n$, the diameter $d_{\mathrm{kr}}$ and melt weight $G_{\mathrm{tav}}$, using the previous expressions (1) - (7) and assuming that the total temperature before the nozzle is $T_{0}=25^{\circ} \mathrm{C}$, then for oxygen converter following relationship is valid

$d_{\mathrm{kr}}=0.00751 \cdot G_{\mathrm{tav}}^{0.446} \cdot \frac{1}{\sqrt{n}}$

and this expression for hearth furnace

$d_{\mathrm{kr}}=0.00298 \cdot G_{\mathrm{tav}}^{0.5505} \cdot \frac{1}{\sqrt{n}}$

Graphic representation of critical diameter change, which are expressed by relation (8) is in Fig. 7.

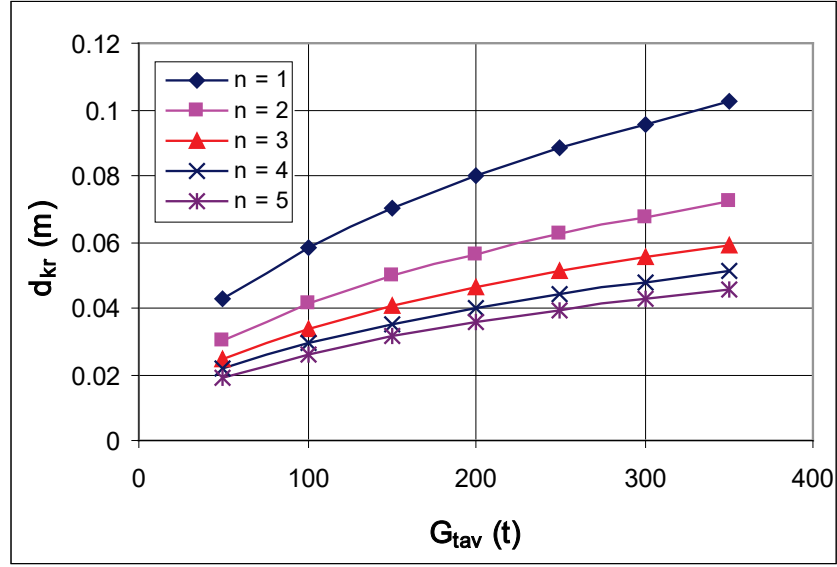

Figure 7 Functional dependence $d_{\mathrm{kr}}=f\left(G_{\mathrm{tav}}\right)$
An important characteristic of the oxygen nozzle is the ratio of the output and critical cross-section $\left(S_{\mathrm{v}}\right.$ and $\left.S_{\mathrm{kr}}\right)$ expressed depending on the ratio of the stagnation pressure in front of output cross-section of the nozzle $p_{\text {ok }}$ (surrounding environment pressure) and stagnation pressure in front of the nozzle $p_{\mathrm{o}}[15]$. For convergent-divergent nozzle in design mode, condition $p_{\mathrm{ok}}=p_{\mathrm{v}}$ is valid, where $p_{\mathrm{v}}$ is the static pressure in the output cross-section. Then following relation is valid.

$\frac{S_{\mathrm{v}}}{S_{\mathrm{kr}}}=\frac{0.24943}{\left[\left(\frac{p_{\mathrm{ok}}}{p_{\mathrm{o}}}\right)^{1.46}-\left(\frac{p_{\mathrm{ok}}}{p_{\mathrm{o}}}\right)^{1.73}\right]^{0.5}}$

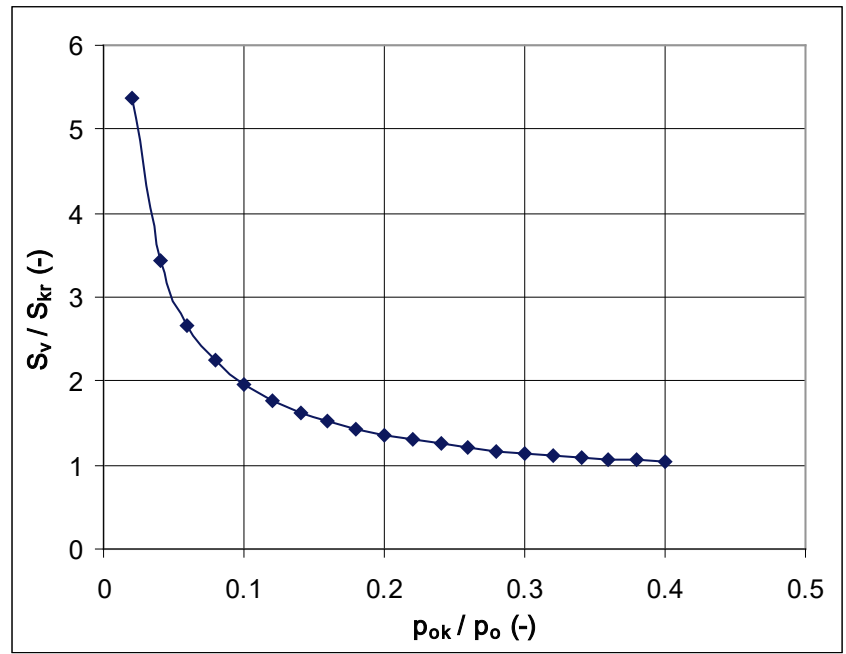

Figure 8 Functional dependence $S_{\mathrm{v}} / S_{\mathrm{kr}}=f\left(p_{\mathrm{ok}} / p_{\mathrm{o}}\right)$

This function (10) is graphically shown in the Fig. 8 and Fig. 9 shows selected nozzle dimensions and parameters.

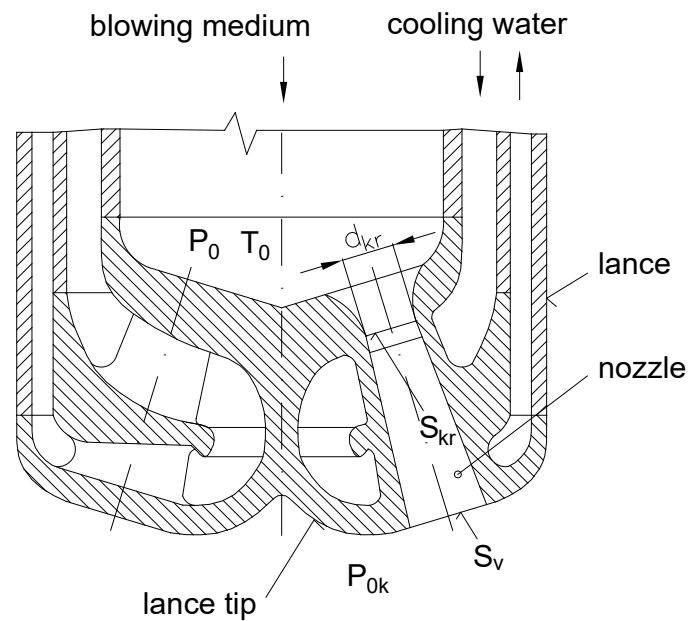

Figure 9 Representation of selected dimensions and areas of the nozzle

\section{CONCLUSION}

Quality of blowing systems for high-temperature reactors for metal production and processing is a necessary 
prerequisite for quality and continuous production. Utility properties of blowing systems depends, among other things, especially on high-quality design of their construction.

The main results of the presented article are the following:

1) operating requirements for lances (nozzles) have been established,

2) requirements for lance (nozzle) design have been established,

3) formulas (1), (2), (3) and (4) may be used to determine the maximum mass flow and total pressure before the nozzle for oxygen converter and hearth furnace, provided that the flow conditions are observed (see Chapter 5),

4) formulas (8), (9) and (10) were derived to calculate the critical nozzle diameter for oxygen converter and hearth furnace,

5) the area (diameter) of the nozzle output cross-section can be determined using formula (11).

Selected main design recommendations and characteristics that were mentioned in the submitted paper help designers and engineers to design systems that meet the high demands on service life, quality, efficiency and operational reliability [16].

\section{Acknowledgments}

This paper was created with the support of the SGS project at the Department of Production Machines and Design, Faculty of Mechanical Engineering VSB-TU Ostrava.

\section{List of used symbols}

$Q_{\text {m-max }}$ oxygen mass flow rate, $\mathrm{kg} \cdot \mathrm{s}^{-1}$

$G_{\text {tav }} \quad$ weight of the melt, $\mathrm{t}$

$p_{\mathrm{o}} \quad$ oxygen stagnation pressure before the nozzle, $\mathrm{MPa}$

$d_{\mathrm{kr}} \quad$ critical diameter, $\mathrm{m}$

$T_{0} \quad$ stagnation temperature, $\mathrm{K}$

$n \quad$ number of nozzles in tuyere, -

$S_{\mathrm{v}} \quad$ output cross-section, $\mathrm{m}^{2}$

$S_{\mathrm{kr}} \quad$ critical cross-section, $\mathrm{m}^{2}$

$p_{\mathrm{v}} \quad$ static pressure in the output cross-section, MPa

$p_{\mathrm{ok}} \quad$ static pressure in the environment into which the

gas stream flows, $\mathrm{MPa}$

$p_{\mathrm{ok}}=p_{\mathrm{v}}$

$R \quad$ specific gas constant, $\mathrm{J} \cdot \mathrm{kg}^{-1} \cdot \mathrm{K}^{-1}$

$\kappa \quad$ adiabatic coefficient, -

\section{REFERENCES}

[1] Bhatacharya, T. et al. (2016) Design considerations of supersonic oxygen lances for a basic oxygen furnace (BOF). $5^{\text {th }}$ International Conference on Process Development in Iron and Steelmaking including $2^{\text {nd }}$ International Process Integration Forum for the Steel Industry, SCANMET V, Lulea, 13-15 June, Sweden. p 1-10
[2] Li, M. M., Li, Q., Li, L., He, Y. B., \& Zou, Z. S. (2014). Effect of operation parameters on supersonic jet behaviour of BOF six-nozzle oxygen lance. Ironmaking \& Steelmaking, 41(9), 699-709. https://doi.org/10.1179/1743281213y.0000000154

[3] Kovář, L. (2015) Bottom tuyeres of high temperatures units division, requirements and selected operating parameters. Conference Proceedings of METAL 2015, $24^{\text {th }}$ International Conference on Metallurgy and Materials, June 3-5, 2015, Hotel Voronez I, Brno, Czech Republic, EU. Ostrava, Tanger, 135-139. ISBN 978-80-87294-62-8.

[4] Snigdha, G., Bharath, B. N., \& Viswanathan, N. N. (2019). BOF process dynamics. Mineral Processing and Extractive Metallurgy, 128(1-2), 17-33. https://doi.org/10.1080/25726641.2018.1544331

[5] Tripathi, P., Kumar, D. S., Sah, R., \& Sekhar, V. R. (2017). An improved lance design for hot metal de-sulphurisation, Ironmaking \& Steelmaking, 44(6), 421-429. https://doi.org/10.1080/03019233.2016.1214379

[6] Lakshmi, M. V. \& Chandra Mouli, K. V. V. N. R. (2017). Study of Oxygen Blowing Lance and It's Drive Mechanism in LD Converters. International Journal \& Magazine of Engineering, Technology, Management and Research, 4(4), 53-62. ISSN 2348-4845.

[7] Naito, K., et al. (2013). Behavior of Top-blowing Lance Jets in BOF. Nippon Steel Technical Report, 104, 33-41.

[8] Wang, H., Zhu, R., Gu, Y. L., \& Wang, C. J. (2014). Behaviours of supersonic oxygen jet injected from four-hole lance during top-blown converter steelmaking process. Canadian Metallurgical Quarterly, 53(3), 367- 380. https://doi.org/10.1179/1879139514Y.0000000128

[9] Liu, F., Sun, D., Zhu, R. et al. (2019) Characteristics of Flow Field for Supersonic Oxygen Multijets with Various Laval Nozzle Structures. Metallurgical and Materials Transactions B, 50, 2362-2376. https://doi.org/10.1007/s11663-019-01652-7

[10] Cao, L. L., Liu, Q., Wang, Z., \& Li, N. (2018). Interaction behaviour between top blown jet and molten steel during BOF steelmaking process. Ironmaking \& Steelmaking, 45(3), 239248. https://doi.org/10.1080/03019233.2016.1255373

[11] See http://ispatguru.com/oxygen-blowing-lance-and-its-rolein-basic-oxygen-furnace/

[12] Mikolajek, J. (1985) Steelworks equipment I. Textbook VSB Ostrava, 206p.

[13] See http://www.nagpalengineering.com/ products/watercooled-oxygen-lance-bof-eaf/

[14] Feng, C., Zhu, R., Han, B. et al. (2020). Effect of Nozzle Exit Wear on the Fluid Flow Characteristics of Supersonic Oxygen Lance. Metallurgical and Materials Transactions B, 51, 187199. https://doi.org/10.1007/s11663-019-01722-w

[15] Mikolajek, J., Trávníček R., \& Kovář L. (1989). Modeling of the oxygen blowing process in the hearth furnace. Interim research report VSB Ostrava on economic contract No. $165 / 88,88 \mathrm{p}$.

[16] Kitamura, S., Naito, K. \& Okuyama, G. (2019). History and latest trends in converter practice for steelmaking in Japan. Mineral Processing and Extractive Metallurgy, 128(12), 34-45. https://doi.org/10.1080/25726641.2018.1504661 
Pavel Novak, Ing.

(Corresponding author)

VSB-Technical University of Ostrava

Faculty of Mechanical Engineering,

Department of Production Machines and Design,

17. listopadu 15/2172, 70833 Ostrava - Poruba, Czech Republic

pavel.novak.st1@vsb.cz

Tomas Hapla, Ing.

VSB-Technical University of Ostrava,

Faculty of Mechanical Engineering,

Department of Production Machines and Design,

17. listopadu 15/2172, 70833 Ostrava - Poruba, Czech Republic

tomas.hapla@vsb.cz 